\title{
LA FINANCIACIÓN DE LA EDUCACIÓN EN EL ESTADO AUTONÓMICO Y SU COHERENCIA CON LA DISTRIBUCIÓN DE COMPETENCIAS EDUCATIVAS
}

EVA SÁENZ ROYO

(C) UNED. Revista de Derecho Politico

N.o 111, mayo-agosto 2021 
SUMARIO

1. INTRODUCCIÓN. 2. ANTECEDENTES HISTÓRICOS. 3. DISTRIBUCIÓN DE COMPETENCIAS EN EDUCACIÓN EN LA CONSTITUCIÓN ESPAÑOLA. 4. LAS COMPETENCIAS ASUMIDAS POR EL LEGISLADOR ESTATAL. 5. LA ASUNCIÓN DE COMPETENCIAS EN EDUCACIÓN POR LAS COMUNIDADES AUTÓNOMAS. 6. LA FINANCIACIÓN DE LA EDUCACIÓN. 6.1. La inversión en centros y la financiación de conciertos. 6.2. Las becas estatales en los Presupuestos Generales del Estado: regulación y financiación estatal; ¿gestión descentralizada? 6.3. El profesorado. 6.4. Las políticas educativas propias de las Comunidades Autónomas con cargo a sus presupuestos. 6.5. El poder de gasto en el marco de las relaciones intergubernamentales para incentivar determinadas políticas autonómicas. 7. CONCLUSIONES Y VALORACIÓN PERSONAL. 


\title{
LA FINANCIACIÓN DE LA EDUCACIÓN EN EL ESTADO AUTONÓMICO Y SU COHERENCIA CON LA DISTRIBUCIÓN DE COMPETENCIAS EDUCATIVAS
}

\author{
EVA SÁENZ ROYO \\ Universidad de Zaragoza ${ }^{1}$
}

\section{INTRODUCCIÓN}

El derecho a la educación incluye, junto a su contenido primario de derecho de libertad, una dimensión prestacional, en cuya virtud los poderes públicos habrán de ejercer su función presupuestaria para hacerlo efectivo. Este ejercicio de la función presupuestaria pública resulta imprescindible para garantizar la gratuidad que se predica constitucionalmente para los niveles básicos de la enseñanza (art. 27.4 CE). Pero también resultará imprescindible para hacer efectivo el derecho a la educación de todos que han de «garantizar los poderes públicos» (art. 27.5 CE) respecto a toda la enseñanza reglada (sea o no obligatoria). Además, la obligación de los poderes públicos de «promover las condiciones para que la libertad y la igualdad del individuo y de los grupos en que se integra sean reales y efectivas» $\mathrm{y}$ «remover los obstáculos que impidan o dificulten su plenitud y facilitar la participación de todos los ciudadanos en la vida política, económica, cultural y social» (art. 9.2 CE) exigirá también de la función presupuestaria pública dirigida a sufragar los costes asociados a la prestación de los servicios educativos de los colectivos más desfavorecidos.

Esta función garantizadora de las prestaciones educativas que asumen los poderes públicos se ha traducido en gasto: en educación no universitaria, el gasto público representó en 2017 el 86\% del gasto educativo total. En el ámbito de la educación universitaria, el gasto público representó en 2017 el $66 \%{ }^{2}$.

1 Eva Sáenz Royo. Profesora Titular de Derecho Constitucional. Universidad de Zaragoza. Facultad de Derecho, Pedro Cerbuna 12, 50009, Zaragoza. Correo electrónico: evasaenz@unizar.es. ORCID: 0000-0002-5502-3870

2 Panorama de la educación. Indicadores de la OCDE 2019. Informe español. Ministerio de Educación y Formación Profesional. Madrid, 2019, p. 58. En Línea: https://www.educacionyfp.gob.es/dam/jcr:b8f-

(C) UNED. Revista de Derecho Politico

N.o 111, mayo-agosto 2021, págs. 45-76 
Como norma general, y de acuerdo con reiterada jurisprudencia constitucional ${ }^{3}$, el ejercicio de esa función presupuestaria (arts. 66.2 y 134.1 CE) debe ser coherente con el sistema de distribución de competencias. De manera que, el régimen normativo y de gestión anejo al gasto se debe ajustar estrictamente al sistema de distribución competencial diseñado por el bloque de constitucionalidad. Solo en el marco de las relaciones intergubernamentales y de la voluntariedad de las CCAA, podría el Estado ejercer su poder de gasto al margen del sistema competencial para la consecución de objetivos entendidos de interés general ${ }^{4}$. Por tanto, como norma general, los presupuestos y la financiación de la educación han de ser reflejo de las decisiones asumidas en el marco del sistema de distribución de competencias. La congruencia entre responsabilidad legislativa y responsabilidad de gasto exigiría que la financiación de los servicios se hiciera recaer sobre el que decide su implantación. Esta correspondencia ayudaría también a distinguir las diferentes responsabilidades en el Estado Autonómico y con ello facilitar el control democrático de las decisiones.

A lo largo de este artículo analizaremos el sistema de distribución competencial en la prestación educativa para, a continuación, valorar su congruencia con la financiación de la misma.

\section{ANTECEDENTES HISTÓRICOS}

El dominio de la iniciativa privada, y concretamente de la Iglesia ${ }^{5}$, será la nota definitoria en la historia de nuestro sistema educativo. El papel subsidiario asumido por los poderes públicos encontrará su primera manifestación en los entes locales, cuya responsabilidad queda constitucionalizada con la Constitución de Cádiz ${ }^{6}$. También

3deec-3fda-4622-befb-386a4681b299/panorama\%20de\%20la\%20educaci\%C3\%B3n\%202019.pdf (consultado 15/5/2020).

3 La doctrina general sobre el alcance del poder de gasto ha sido profusamente reiterada. Especialmente importante fue la STC 13/1992, de 6 de febrero, FFJJ 7, 10. Otras han sido: SsSTC 39/1982, de 30 de junio, FJ 5; 144/1985 de 25 de octubre, FJ 4; 179/1985, de 19 de diciembre, FJ 1; 95/1986, de 10 de julio, FJ3; 96/1986, de 10 de julio, FJ 2; 146/1986, e 25 de noviembre, FFJJ 3, 4; 88/1987, de 2 de junio, FJ 2; 201/88, de 27 de octubre, FJ 2; 227/1988, de 29 de noviembre, FJ 27; 14/1989, de 26 de enero, FJ 2; 75/1989, de 21 de abril, FJ2; 145/89, de 21 de septiembre, FJ 2; 188/1989, de 16 de noviembre, FJ 3; 96/1990, de 24 de mayo, FJ 15; 17/1991, de 31 de enero, FJ 13; STC 79/1992, de 28 de mayo, FJ 2; 202/1992, de 23 de noviembre, FJ 6; 213/1994, de 14 de julio, FJ 4; 59/1995, de 17 de marzo, FJ 2.

4 Sáenz Royo, E. (2013). «Relaciones intergubernamentales de carácter vertical en el Estado Autonómico: el ser, el deber ser y posibles retos de futuro». REDC, 97, p. 47-62.

5 Embid Irujo, A. (1983). Las libertades en la Enseñanza, Madrid, Tecnos, pp. 194-206.

6 Mientras el art. 366 establece la obligación de establecer escuelas de primeras letras en todos los pueblos de la Monarquía, el art. 310 ordena generalizar también la institución de los Ayuntamientos en estos pueblos. Vid. Embid Irujo, A. (2000). «Un siglo de legislación musical en España (Y una alternativa para la organización de las enseñanzas artísticas en su grado superior)», RAP, núm. 153, p. 480. 
entonces se considera necesaria una regulación uniforme en todo el Estado de un «plan general de la enseñanza» (art. 368), teniendo las Cortes un papel esencial (art. 370).

Las regulaciones estatales en materia educativa, iniciadas ya durante el siglo XVIII ${ }^{7}$, empiezan a tener especial relevancia durante el período moderado que se inicia en 1843 y que, salvo la interrupción del bienio progresista, continuará con la Unión Liberal hasta 1868. La Ley de Instrucción Pública de 9 de septiembre de 1857 (Ley Moyano) va a consagrar la competencia del Estado en materia de instrucción. Establece, por una parte, el monopolio estatal en cuanto a las Universidades y a las escuelas superiores y profesionales y, por otra parte, un control público sobre la enseñanza privada.

A partir del desastre del 98 y con el consiguiente nacimiento del regeneracionismo el Estado comienza a tomar conciencia de la importancia de, no sólo regular e influir sobre la educación, sino también de financiarla. Expresión gráfica del creciente interés del Estado por la educación será la creación por Real Decreto de 18 de abril de 1900 del Ministerio de Instrucción Pública y Bellas Artes ${ }^{8}$. Una de las primeras decisiones adoptadas por este Ministerio (Real Decreto de 26 de octubre de 1901) supondrá la asunción por el Estado, si no de todas las obligaciones con relación a la enseñanza ${ }^{9}$, sí de la parte más gravosa como es el pago de los sueldos de los maestros de las Escuelas Públicas (art. 10), exceptuándose de la generalidad de esta medida sólo los sueldos de los maestros de las Escuelas Públicas de las provincias vascongadas y Navarra «hasta tanto que se celebre concierto con las Diputaciones Forales». Merece la pena destacar también, desde el punto de vista prestacional, la inauguración de una política de ayudas para ampliar estudios en el extranjero por Real Decreto de 18 de julio de 1901 .

Si bien los debates presupuestarios sobre la instrucción pública del primer tercio del siglo XX en España estuvieron marcados por una conciencia de necesaria ampliación de los recursos, resulta clara la falta de una política de gasto decidida en este sector $^{10}$. La Dictadura de Primo de Rivera constituyó un esfuerzo notable, aunque no suficiente, especialmente en la lucha contra el analfabetismo y en la construcción de escuelas ${ }^{11}$. La escolarización se amplió a los 14 años, siendo gratuita y obligatoria (art. 5 del Estatuto de 18 de mayo de 1923).

Un salto cualitativo representó la Constitución republicana de 1931. En su art. 48 se señala que la materia educativa es considerada como una «atribución esencial del Estado» y en consecuencia se garantiza su prestación a través de instituciones públicas,

7 Gómez-Ferrer Morant, R. (1973). «El régimen general de los centros privados de enseñanza», RAP, núm. 70, p. 10.

8 Embid Irujo, A. (2000), ob. cit., p. 475.

9 Los Ayuntamientos siguen encargándose de los «gastos de arrendamientos de casas, escuelas y habitaciones de los Maestros, así como los de construcción y reparación de locales destinados a estos servicios» (art. 12 del Real Decreto de 26 de octubre de 1901).

10 De Puelles Benítez, M. (2000). «Política escolar y debate público en la España del primer tercio del siglo Xx: el problema de los recursos», Sistema, núm. 154, pp. 33 y ss.

11 Ibid., p. 56.

(C) UNED. Revista de Derecho Politico

N.o 111, mayo-agosto 2021, págs. 45-76 
se reconoce la gratuidad de la enseñanza obligatoria, se prevé la ayuda para facilitar a los españoles económicamente necesitados el acceso a todos los grados de enseñanza y se reduce el derecho de las Iglesias a enseñar sus doctrinas en su propios establecimientos, derecho que además está sujeto a la inspección del Estado. Obsérvese que, frente al federalismo de corte liberal del proyecto de Constitución federal de 17 de julio de $1873^{12}$, la Constitución de 1931 convierte la educación en una prestación centralizada, donde el Estado se considera el máximo y primer responsable. Es el Estado el que acapara su regulación, la expedición de títulos y la Alta Inspección, dejando a las regiones autónomas la organización de la enseñanza de sus lenguas (arts. 49 y 50).

En la práctica, se puso en marcha la conocida laicización de la enseñanza que supuso la prohibición a las Órdenes religiosas de dedicarse a la misma. Esta prohibición estaba prevista en el art. 26 de la Constitución y desarrollada por el art. 30 de la Ley de Congregaciones Religiosas de 1933. También el bienio azañista de la II República supuso el aumento de los sueldos de maestros, una ampliación hasta entonces desconocida de las plantillas, la construcción acelerada de escuelas públicas, la modernización de la formación de maestros, el reclutamiento masivo del profesorado de primeras letras... Este bienio desde un punto de vista presupuestario y prestacional se caracterizó por el notable incremento de las partidas presupuestarias dedicadas a la instrucción primaria y por la realización de un esfuerzo extraordinario para acabar con el analfabetismo mediante la construcción de edificios escolares (Ley de 16 de septiembre de 1932) ${ }^{13}$.

La guerra civil puso fin a este empeño republicano. Durante los veinte primeros años del franquismo se dio una clara preponderancia del sector privado y de la Iglesia en la educación. Fue clara muestra la nula construcción de institutos durante los veinte primeros años del régimen ${ }^{14}$. Consecuencia necesaria de la modernización en la sociedad española comenzada en la década de los sesenta será la Ley General de Educación de 1970. Esta ley supondrá el renacimiento del «derecho docente del Estado». Con ella se concede al Estado potestades importantes sobre la educación, se potencia la enseñanza pública, la actividad de los centros privados queda sometida a una ordenación e intervención muy intensa por parte de la Administración y se anun-

12 Este proyecto de Constitución establece una nítida separación en las competencias de la Federación y de los Estados miembros. Tras enumerar en el Título V las competencias que le corresponden a la Federación, establece en el Título XIII, art. 96, que «Los Estados regirán (....) su instrucción y todos los asuntos civiles y sociales que no hayan sido por esta Constitución remitidos al Poder federal». Entre las competencias enumeradas de la Federación no se hace mención de la educación, salvo lo referente a la creación de una Universidad federal y de cuatro escuelas normales superiores de agricultura, artes y oficios. Las incipientes políticas prestacionales, como la educación, se dejan pues en manos de los Estados, a quienes se impone la obligación de «conservar un Instituto de segunda enseñanza por cada una de las actuales provincias y la facultad de fundar las Universidades y escuelas especiales que estimen conveniente» (art. 98).

13 De Puelles Benítez, M. (2000), ob. cit., p. 56.

14 Pérez Galán, M. (1975). «El bachillerato en España, 1936-1970», en La enseñanza en España, Madrid, Alberto Corazón, pp. 276-277. 
cia un sistema de conciertos con la enseñanza privada, aunque en la práctica se continuará con el tradicional sistema subvencional.

\section{DISTRIBUCIÓN DE COMPETENCIAS EN EDUCACIÓN EN LA CONSTITUCIÓN ESPAÑOLA}

La aprobación de la Constitución española supondrá, además de la consolidación de un sistema educativo dual, público y privado, la cancelación del centralismo en las políticas educativas vigente en España a lo largo de toda su historia.

En el texto del Anteproyecto de la Constitución (BOE de 5 de enero de 1978) se consagraban amplios poderes a las Comunidades Autónomas en materia de enseñanza, limitándose el papel del Estado a establecer los requisitos de expedición y homologación de títulos y convalidación de los estudios académicos y profesionales (art. 138.30 ${ }^{15}$. Salvo demandas aisladas de autonomía plena de las Comunidades Autónomas en esta materia ${ }^{16}$, mayoritariamente se cree en la necesidad de una intervención básica por parte del Estado ${ }^{17}$. Finalmente se opta por una fórmula, adoptada ya en el art. 143.1.28 del Dictamen de la Comisión de Asuntos Constitucionales y Libertades Públicas sobre el Anteproyecto de Constitución (Boletín Oficial de las Cortes de 1 de julio de 1978), en la que a la regulación estatal de las condiciones de obtención, expedición y homologación de títulos académicos y profesionales se añaden las normas básicas para el desarrollo del artículo en que se recoge el derecho a la educación «a fin de garantizar el cumplimiento de las obligaciones de los poderes públicos en esta materia» (art. 149.1.30) ${ }^{18}$. En definitiva, al Estado se le otorga una competencia normativa plena en las condiciones de obtención de títulos oficiales, una competencia

15 Se manifiesta a favor de esta redacción originaria del Anteproyecto el Grupo Parlamentario del Partido Nacionalista Vasco en la Enmienda que defiende Aguirre Querexeta en el Debate en el Pleno del Congreso de los Diputados (Diario de Sesiones del Congreso de los Diputados de 20 de julio de 1978).

16 En la Enmienda núm. 202 que presenta el Grupo Parlamentario de la Minoría Catalana al Anteproyecto de Constitución a los efectos de modificar la redacción del art. 138 en su totalidad, se reserva a los Territorios Autónomos la legislación exclusiva y la ejecución en educación y enseñanza en todos sus grados.

17 Vid. Voto Particular del Grupo Parlamentario Socialistas del Congreso al art. 138 del Anteproyecto; las Enmiendas al art. 138 del Anteproyecto núm. 101 (de los Diputados Josep Verde i Aldea, Jon Paredes i Hernández y don Josep Pau Pernau pertenecientes a Minoría Catalana), 309 (Grupo Parlamentario Socialistes de Catalunya) y 357 (Grupo Socialista del Congreso).

18 Lo que sería la redacción definitiva del título competencial estatal en materia educativa fue defendida en la Enmienda «in voce» suscrita por UCD y defendida por Meilán Gil en el Debate en la Comisión de Asuntos Constitucionales y Libertades Públicas (Diario de Sesiones del Congreso de los Diputados de 15 de junio de 1978).

(C) UNED. Revista de Derecho Politico

N.o 111, mayo-agosto 2021, págs. 45-76 
ejecutiva plena es su expedición y homologación y una competencia básica en la regulación de otros aspectos relacionados con el artículo $27^{19}$.

Por tanto, la atribución al Estado de competencias normativas básicas en políticas educativas, asegura un nivel básico común de prestaciones educativas en todo el territorio. En un primer momento, se interpretó por parte del Tribunal Constitucional ${ }^{20}$ que en materia educativa la regulación correspondía exclusivamente al Estado, excluyendo los poderes normativos autonómicos. No será hasta la STC 137/1986, de 6 de noviembre, cuando nuestro Alto Tribunal reconozca que al Estado sólo le corresponde la normación básica a la que se refiere el art. 149.1. 30 CE, legitimando los poderes normativos autonómicos en todo aquello que no sea la regulación de lo básico.

Además, desde mi punto de vista, se excluye del ámbito educativo la aplicación del art. 149.1.1 CE. Como ha señalado el Tribunal Constitucional «La mayor especificidad del art. 149.1.30 CE se deriva de que mientras que la regla 1 del art. 149.1 CE se proyecta de modo genérico sobre todos los derechos fundamentales, el art. 149.1.30 CE, lo hace, de modo específico, sobre el derecho a la educación» (STC 188/2001, de 20 de septiembre).

El artículo 149.1.1 CE permite al Estado establecer la regulación básica de los derechos y deberes constitucionales en general, sin que quepa distinción respecto de la competencia básica otorgada respecto al art. 27 CE por el art. 149.1.30 CE. Así, el art. 149.1. 1 faculta al Estado a establecer un régimen jurídico unitario en todo el territorio nacional limitado a «las condiciones básicas», reproduciendo así el esquema bases/desarrollo presente en otros títulos competenciales.

Lo que singulariza a este título competencial es que se define en referencia, no a una materia concreta, no a los derechos y deberes constitucionales, sino a un objetivo, la garantía de «la igualdad de todos los españoles en el ejercicio de los derechos y en el cumplimiento de los deberes constitucionales». Sin embargo, no creo que esto pueda significar una gran diferencia por cuanto entiendo que tanto la legislación básica del derecho a la educación como «la regulación de las condiciones básicas» para garantizar «la igualdad de todos los españoles en el ejercicio de los derechos y en el cumplimiento de los deberes constitucionales» pueden incluir la regulación de aspectos organizativos o la regulación de la materia sobre la que se proyecta el derecho, ya que estos aspectos no pueden considerarse ajenos al contenido mismo del derecho, visto desde su perspectiva objetiva y ya no solo objetiva ${ }^{21}$.

19 Aragón Reyes, M. (2013). «Las competencias del Estado y las Comunidades Autónomas sobre educación», Revista Española de Derecho Constitucional, 98, p. 194.

20 Vid. STC 5/1981, de 13 de febrero; STC 25/1981, de 14 de julio.

21 En este sentido, Sáenz Royo, E. (2003). Estado social y descentralización política. Una perspectiva constitucional comparada de Estados Unidos, Alemania y España, Thomson-Civitas/Gobierno de Aragón, pp. 279-293. Autores como Aragón Reyes mantienen que sí existe una diferencia al señalar que «La normativa básica (en su función igualatoria) está al servicio del artículo 14 CE, y la regulación de las «condiciones básicas» al servicio no sólo del artículo 14 CE sino también del artículo 9.2 CE. Ambas competencias no son, pues, excluyentes sino complementarias». Vid. Aragón Reyes, M. (2013), ob. cit., p. 195. 
En todo caso, la regulación estatal sobre la educación deberá hacerse, primeramente, a través de ley orgánica en virtud del artículo 81 CE. Este artículo no puede entenderse como título de distribución competencial, sino un precepto relativo al sistema de fuentes. Como recuerda Otto y Pardo, la estructura del art. 81.1 es semejante a la del art. 19 de la Ley Fundamental de Bonn, por cuanto se efectúan previsiones para los casos en que el legislador tenga, por obra de otra norma, poder de incidir de determinado modo sobre los derechos fundamentales. Es decir: el art. 81.1 «no dice qué derechos podrán ser objeto de desarrollo, sino tan sólo cómo habrá de ser formalmente éste» ${ }^{22}$. En cualquier caso, la reserva de ley orgánica es materialmente menor que la regulación básica desde el momento en el que la regulación básica puede hacerse también por reglamentos. Lo que está constitucionalmente reservado a la Ley orgánica es «la regulación de determinados aspectos esenciales para la definición del derecho, la previsión de su ámbito y la fijación de sus límites en relación con otras libertades constitucionalmente protegidas» (STC 173/1998, FJ 7; 88/1995, FJ 4; 140/1986, FJ 5; 101/1991, FJ 2 y 132/1989, FJ 16). Por tanto, lo regulado por ley orgánica es básico. No obstante, según jurisprudencia constitucional consolidada, no todo lo básico ha de estar regulado por ley orgánica, permitiendo ley ordinaria e incluso reglamento ${ }^{23}$.

En definitiva, las competencias compartidas en materia educativa reclaman que para la íntegra regulación de esta materia se complementen el legislador estatal y el autonómico, gozando cada uno de ellos de exclusividad en su ámbito propio (STC 71/1983, FJ 2), de manera que ni las Comunidades Autónomas pueden contravenir la «regulación normativa uniforme y de vigencia en toda la nación» en que consisten las bases, ni a éstas les está permitido adquirir «tal grado de desarrollo que deje vacía de contenido la correlativa competencia de la Comunidad» (STC 1/1982, FJ 1), pues las bases estatales deben permitir «opciones diversas, ya que la potestad normativa de las Comunidades Autónomas no es, en estos supuestos, de carácter reglamentario» (STC 32/1981, FJ 5).

Otros títulos competenciales del Estado que pueden jugar un papel en la educación son el art. 149.1.15 CE y el art. 149.1.18 CE. El primero se refiere a la competencia exclusiva del Estado de «fomento y coordinación general de la investigación científica y técnica». El segundo se refiere a la competencia estatal sobre «las bases del régimen jurídico de las Administraciones públicas y del régimen estatutario de sus funcionarios», lo cual afecta a los centros docentes públicos como Administración pública educativa y a sus funcionarios (incluidos los profesores).

22 De Otto y Pardo, I. (1988). «La regulación del ejercicio de los derechos y libertades. La garantía de su contenido esencial en el artículo 53.1 de la Constitución», en Martín-Retortillo, L. y De Otto y Pardo, I., Derechos fundamentales y Constitución, Madrid, Civitas, p. 106.

23 Cotino Hueso, L. (2012). El Derecho a la educación como derecho fundamental. Especial atención a su dimensión social prestacional, Madrid, Centro de Estudios Políticos y Constitucionales, p. 306.

(C) UNED. Revista de Derecho Politico

N.o 111, mayo-agosto 2021, págs. 45-76 
Al margen de estas competencias corresponde al Estado el ejercicio de la Alta Inspección en materia de Enseñanza ${ }^{24}$. Se ha dicho que esta competencia, que ya en la Constitución republicana de 1931 se hallaba expresamente atribuida al Estado (art. 50), no se encuentra regulada por la Constitución, estando presente su reflejo normativo en los Estatutos de Autonomía y en la legislación ${ }^{25}$. No es difícil, sin embargo, encontrar el fundamento constitucional de esta función en el último inciso del art. 149.1.30 cuando señala que corresponde al Estado las normas básicas para el desarrollo del art. 27 de la Constitución «a fin de garantizar el cumplimiento de las obligaciones de los poderes públicos en esta materia». Este párrafo supone una adición a la competencia estatal inicialmente prevista en el Anteproyecto de la Constitución. Precisamente la interpretación del mismo que propone Solé Tura en su explicación de voto ${ }^{26}$ otorgaría al Estado lo que se entiende como Alta Inspección para garantizar que las Comunidades Autónomas cumplan con sus obligaciones. De hecho, los Estatutos de Autonomía de las Comunidades con un techo competencial inicialmente más elevado y con acceso, por tanto, a competencias en esta materia, reservaron la Alta Inspección al Estado en educación ${ }^{27}$.

De la STC 6/1982, de 22 de febrero, y de pronunciamientos posteriores ${ }^{28}$, se interpreta que la función de la Alta Inspección solamente se puede entender como de relación informativa entre la Administración estatal y la autonómica, que puede dar lugar a la puesta en funcionamiento de los controles judiciales ordinarios ${ }^{29}$. En este sentido, la Alta Inspección puede requerir una intervención directa en los centros docentes, aunque sólo para fiscalizar el cumplimiento de los contenidos normativos estatales y para discernir las posibles disfunciones en las competencias estatales y autonómicas. Concretamente, en la STC 6/1982, el Tribunal entendió que la Alta Inspección podía ejercerse legítimamente para velar por el respeto de las normas estatales y los derechos lingüísticos de todos los españoles, en particular, por el dere-

24 En ejercicio de esta competencia el Estado aprobó el Real Decreto 480/1981, de 6 de marzo, sobre el funcionamiento en el País Vasco y Cataluña de la Alta Inspección del Estado en materia de Enseñanza no universitaria; el Real Decreto 1982/1983, de 23 de mayo, sobre funcionamiento en las Comunidades Autónomas de la Alta Inspección del Estado en materia de Enseñanza no universitaria; y el Real Decreto 1950/1985, de 11 de septiembre, por el que se crean, en materia de Enseñanza, los Servicios de Alta Inspección del Estado.

25 Embid Irujo, A. (1989). «La ampliación de competencias educativas», Revista jurídica de Navarra, núm. 7, p. 23.

26 Debate en el Pleno del Congreso de los Diputados, Diario de Sesiones del Congreso de los Diputados de 20 de julio de 1978.

27 Vid. arts. 16 y 18 Estatuto de Autonomía del País Vasco; arts. 15 y 17 Estatuto de Autonomía Catalán; arts. 31 y 33 Estatuto de Autonomía de Galicia; arts. 19 y 20 Estatuto de Autonomía de Andalucía; arts. 47 y 54 LORAFNA.

28 SsTC 44/1982, de 8 de julio; 32/1983, de 28 de abril; 42/1983, de 20 de mayo; 76/1983, de 5 de agosto; 54/1990, de 28 de marzo; 38/1992, de 23 de marzo; STC 14/2018, de 20 de febrero.

29 Diego Casals, J. L. (1989). Las competencias de la Comunidad Autónoma en materia de educación, Oñati, HAEE/IVAP, p. 119; Lasagabaster Herralte, I. (1993). «Enseñanzas y Estado de las autonomías», Autonomies, núm. 17, p. 38. 
cho a recibir la enseñanza en la lengua oficial del Estado. Se reduce así la competencia del Estado a la de «vigilancia» para «propiciar la corrección de los fallos que se detecten» (pero no para llevar a cabo, directamente, esa corrección) $)^{30}$.

\section{LAS COMPETENCIAS ASUMIDAS POR EL LEGISLADOR ESTATAL}

En la práctica, siendo la materia educativa -sobre la no universitaria- en España una cuestión de grandes discrepancias políticas, el legislador estatal, en función de las mayorías parlamentarias, ha procedido a sucesivas modificaciones durante estos cuarenta años ${ }^{31}$.

Ya en 1985 el legislador estatal se reservó una competencia regulativa de mínimos, en coherencia con lo establecido en el art. 149.1.30 CE, en el ámbito prestacional de creación de centros docentes (art. 27.5 CE) o de ayuda a aquéllos que reúnan los requisitos establecidos en la Ley (art. 27.9 CE). En este sentido, es el gobierno estatal quien fijará los requisitos mínimos que han de reunir los centros docentes para impartir enseñanzas con garantía de calidad (art. 14 LODE). Competencia regulativa de mínimos que se ejerce también por medio de Reales Decretos. Así, el Real Decreto 132/2010, de 12 de febrero, por el que se establecen los requisitos mínimos de los centros que impartan las enseñanzas del segundo ciclo de la Educación Infantil, la Educación Primaria y la Educación Secundaria. También, el Real Decreto 2377/1985,

30 Precisamente se interpreta en la STC 14/2018, de 20 de febrero, que la concesión de ayudas públicas para garantizar la enseñanza en la lengua oficial del Estado en centros privados para el caso de incumplimiento por la Administración educativa autonómica de esta enseñanza prevista en la DA 38.4 LOE modificada por la LOMCE supone una «indebida asunción directa y exclusiva por el Estado de una competencia de ejecución propia de la Comunidad Autónoma» (FJ 11).

Critica esta interpretación Aragón Reyes al considerar que se trata de una competencia «degradada en su capacidad, en cuanto circunscrita a una actividad inspectora meramente informativa». Aragón Reyes, M. (2013), ob. cit., p. 197. En la misma línea Vidal Prado, C. (2018). «Descentralización y derechos educativos, 40 años después», en Álvarez Vélez, M. I. y Vidal Prado, C. (coords). La Constitución Española: 1978-2018: Manual, Ediciones Francis Lefebvre, pp. 343-344.

31 Ley Orgánica 5/1980, de 19 de julio, del Estatuto de los Centros docentes (LOECE); Ley Orgánica 8/1985, de 3 de julio, reguladora del derecho a la educación (LODE) (todavía vigente básicamente en lo realtivo a los derechos y deberes de padres y alumnos en centros educativos privados); Ley Orgánica 1/1990, de 3 de octubre, de Ordenación General del sistema Educativo (LOGSE); Ley Orgánica 9/1995, de 20 de noviembre, de Participación, Evaluación y Gobierno de los Centros Docentes (LOPEG); Ley Orgáncia 10/2002, de 23 de diciembre, de Calidad de la Educación (LOCE), que no llegó a implantarse; Ley Orgánica 2/2006, de 3 de mayo, de Educación (LOE); Ley Orgánica 8/2013, de 9 de diciembre, para la mejora de la calidad educativa (LOMCE); Ley Orgánica 3/2020, de 29 de diciembre, por la que se modifica la Ley Orgánica 2/2006, de 3 de mayo, de Educación (LOMLOE).

A pesar de las sucesivas modificaciones, Vidal Prado afirma que desde la aprobación de la LODE en 1985 «existe un modelo de sistema educativo en España que no ha sufrido excesivas variaciones». Vidal Prado, C. (2017). «El diseño constitucional de los derechos educativos ante los retos presentes y futuros», Revista de Derecho Político, núm. 100, p. 741.

N.o 111, mayo-agosto 2021, págs. 45-76 
de 18 de diciembre, por el que se aprueba el Reglamento de Normas Básicas sobre Conciertos Educativos.

Por lo demás, el modelo autonómico en materia educativa se ha traducido básicamente durante estos cuarenta años en la fijación por el legislador estatal de la estructura de los niveles educativos y los contenidos mínimos de cada uno de ellos. La LOMCE dividió los niveles educativos en infantil, primaria, secundaria, bachillerato y formación profesional. También dividió las asignaturas en tres tipos de materias: troncales, específicas y de libre configuración autonómica. La administración del Estado fijaba el contenido común de las materias troncales, su horario mínimo y mantenía el control de las evaluaciones finales de la Educación Secundaria Obligatoria y Bachillerato (art. 6bis LOE en redacción dada por la LOMCE). Con la LOMLOE «el Gobierno, previa consulta a las Comunidades Autónomas, fijará, en relación con los objetivos, competencias, contenidos y criterios de evaluación, los aspectos básicos del currículo, que constituyen las enseñanzas mínimas», así como el horario mínimo (arts. 6.3 y 6.4 LOE en redacción por la LOMLOE).

Una de las cuestiones más polémicas es que el legislador estatal no establece de forma objetiva y clara el marco jurídico básico de la enseñanza en castellano, por ejemplo, reservando al Estado la fijación de un mínimo de horas. Entre otras razones, por la falta de un marco jurídico básico, la STC 14/2018, de 20 de febrero, declaró inconstitucional el cauce arbitrado por la LOMCE de concesión de ayudas públicas para la enseñanza en la lengua oficial del Estado (FJ 11). Por tanto, el adjetivo vehicular, que se añadió a la lengua castellana en la DA 38 LOE por la LOMCE y que se ha eliminado por la LOMLOE, nada de seguridad jurídica añadió a este respecto.

También el legislador estatal fija las condiciones de acceso del profesorado funcionarial (art. 149.1.18 y art. 149.1.30 CE) (STC 75/1990, de 26 de abril, FJ 2). En esas condiciones de acceso se incluye «la normativa relativa a la adquisición y perdida de la condición de funcionario, a las condiciones de promoción de la carrera administrativa y a las situaciones que en ésta puedan darse, a los derechos y deberes y responsabilidades de los funcionarios y a su régimen disciplinario» (STC 37/2002, de 14 de febrero, FJ 5). Se trata de una competencia estatal justificada en que «los funcionarios docentes (...) van a desempeñar sus tareas al servicio de un sistema educativo que es único en todo el territorio nacional» (STC 213/2013, de 19 de diciembre, FFJJ 6, 7 y 8).

El legislador estatal determina igualmente las condiciones de acceso a la actividad docente no funcionarial en los colegios privados a partir de su competencia básica en educación (art. 149.1.30 CE). En aplicación a esta competencia estatal, el régimen legal aplicable a la formación y el acceso del profesorado no universitario se encuentra en el Estatuto básico del Empleado Público, en la LOE y en los Reglamentos que desarrollan esta última ley ${ }^{32}$.

32 Meix Cereceda, P. (2015). «La formación y selección del profesorado en el Estado Autonómico», en Caballero Sánchez, R. (dir.), Sistema educativo y descentralización territorial, Iustel, p. 224. 
En el ámbito universitario, el acceso a los cuerpos docentes (profesores funcionarios) está centralizado en su primera fase (acreditación, art. 57 LOU), dejando al a autonomía universitaria la regulación concreta sobre la segunda fase (concurso de acceso, art $62 \mathrm{LOU}$ ). La LOU también establece diferentes figuras de profesorado contratado laboral, exigiendo para algunas de ellas la evaluación externa (que puede ser del órgano nacional -ANECA- o autonómico) y dejando a la regulación universitaria el concurso subsiguiente.

Por último, en lo que respecta a la Alta Inspección, hoy en día se dedica básicamente a la homologación de estudios extranjeros, sin realmente haber una vigilancia de los currículos educativos fijados por el Estado (arts. 149 ss. LOE; DA 23 LOU) $)^{33}$.

\section{LA ASUNCIÓN DE COMPETENCIAS EN EDUCACIÓN POR LAS CCAA}

La Constitución, al establecer diferentes techos competenciales en función del procedimiento de acceso a la autonomía, al dar carácter potestativo a la asunción de competencias y al encomendar la regulación de las mismas a los Estatutos de Autonomía, posibilita que la asunción de competencias en materias educativas difiera grandemente de una Comunidad Autónoma a otra. Pero los hechos han conducido a una práctica uniformidad de las Comunidades Autónomas.

Las Comunidades Autónomas disponen de competencias exclusivas en materia de fomento de la cultura regional (cultura, archivos, bibliotecas, conservatorios y museos que no sean de titularidad estatal, patrimonio histórico y artístico, sin perjuicio de la competencia del Estado para su defensa contra la exportación y la expoliación), de la investigación (investigación científica y técnica, en coordinación con el Estado) y, en su caso, de la enseñanza de su lengua en los supuestos de cooficialidad lingüística, con el objetivo de la normalización de la lengua autóctona (art. 148.1. párrafos 15, 16 y $17 \mathrm{CE}$ ). Dichas competencias fueron previstas originariamente en la relación de materias que podían asumir las Comunidades de régimen común durante sus primeros cinco años de experiencia autonómica, y han sido asumidas estatutariamente con formulaciones normativas semejantes.

Las Comunidades Autónomas cuentan, asimismo, con competencias ejecutivas y de desarrollo legislativo, es decir, de promulgación de normas legales y reglamentarias que no tengan la consideración de básicas, para la regulación del derecho a la educación y la configuración general del sistema educativo. No obstante, esta competencia de desarrollo legislativo y ejecución en materia educativa solamente podía ser asumida inicialmente por las Comunidades Autónomas de primer grado. Dispusieron en primer lugar de competencias en Enseñanza universitaria y no universitaria el País Vasco,

33 Galván Palomo, F. (2011). «Sistema educativo y Alta Inspección», Revista de la Asociación de Inspectores de Educación en España, núm. 15, pp. 3-4.

(C) UNED. Revista de Derecho Politico

N.o 111, mayo-agosto 2021, págs. 45-76 
Cataluña, Galicia, Andalucía y Navarra, habiendo alcanzado una situación similar Canarias y la Comunidad Valenciana en virtud de sendas Leyes Orgánicas de transferencia (art. 150.2 CE) ${ }^{34}$.

Las demás debían esperar al trascurso de los cinco años necesarios para la ampliación de competencias, tal como prescribe el art. 148.2 de la Constitución. Así se puso de manifiesto en los diferentes Estatutos de Autonomía donde la referencia a las competencias autonómicas en materia de enseñanza, referencia por lo demás semejante a la que se hacía en los Estatutos de Autonomía de las Comunidades Autónomas de autonomía inicial amplia, iba acompañada de la advertencia de que sólo puede ser efectiva o mediante un procedimiento de reforma del Estatuto o mediante la emanación de una Ley Orgánica de las que contiene el art. 150.2 de la Constitución. Mención aparte merecía la competencia en materia universitaria, aunque esta diferenciación no fundamentara competencias distintas de las que pudieran provenir por aplicación de la cláusula general sobre enseñanza ${ }^{35}$.

Llegado agosto de 1987 se cumplió el plazo de espera de cinco años establecido en el art. 148.2 CE. El reconocimiento de competencias en esta materia a todas las Comunidades Autónomas no llegaría hasta la Ley 8/1992, de 23 de diciembre, de transferencia de competencias a las Comunidades Autónomas que accedieron a tal condición por la vía del art. 143 de la Constitución y la ha puesto en práctica la Ley Orgánica 9/1992, de 23 de diciembre, que dedica el Título II, arts. 19 y 20, a la transferencia de la enseñanza y al establecimiento de facultades y condiciones de su ejercicio. Se completará el proceso con la inesperadamente rápida incorporación de las competencias recogidas en la misma en los Estatutos de Autonomía en la llamada «segunda fase» de las reformas estatutarias.

Durante los años 1995 y 1996 se cerró el traspaso de funciones y servicios en materia de Universidades a todas las Comunidades Autónomas de vía inicial reducida, tras las reformas estatutarias de $1994^{36}$, permaneciendo en el ámbito de la Adminis-

34 Se traspasan las funciones y servicios en materia de Enseñanza no universitaria a País Vasco, Cataluña, Galicia, Andalucía, Canarias, Valencia y Navarra, respectivamente, por Reales Decretos 2808/80, de 26 de septiembre; 2809/80, de 3 de octubre; 1763/82, de 24 de julio; 3936/82, de 29 de diciembre; 2091/83, de 28 de julio; 2093/83, de 28 de julio; y 1070/90, de 31 de agosto. En materia de Universidades a Cataluña, País Vasco, Comunidad Valenciana, Andalucía, Canarias y Galicia por Reales Decretos 305/85, de 6 de febrero; 1014/85, de 25 de mayo; 2633/85, de 20 de noviembre; 1734/ 86, de 13 de junio; 2802/86, de 12 de diciembre; y 1754/87, de 18 de diciembre. Navarra no tendrá transferencia sino creación de su propia Universidad en la que se integran ciertos centros desgajados de la de Zaragoza (vid. Ley Foral 8/1987, de 21 de abril, de creación de la Universidad Pública de Navarra).

35 Embid Irujo, A. (1989), ob. cit., p. 28.

36 Real Decreto 634/1995, de 21 de abril, sobre traspaso de funciones y servicios de la Administración del Estado a la Comunidad Autónoma de Extremadura; Real Decreto 942/1995, de 9 de junio, sobre traspaso de funciones y servicios de la Administración del Estado a la Comunidad de Madrid; Real Decreto 848/1995, de 30 de mayo, sobre traspaso de funciones y servicios de la Administración del Estado al Principado de Asturias; Real Decreto 948/1995, de 9 de junio, sobre traspaso de funciones y servicios de la Administración del Estado a la Comunidad Autónoma de la Región de Murcia; Real Decreto 907/1995, de 2 de junio, sobre traspaso de funciones y servicios de la Administración del 
tración General del Estado sólo la UNED y la UIMP. Durante 1997, 1998 y 1999 se efectuó también el traspaso de funciones y servicios en materia de enseñanza no universitaria a este conjunto de Comunidades Autónomas de vía inicial reducida ${ }^{37}$. Al ser asumida en los Estatutos de Autonomía por todas las Comunidades Autónomas esta competencia, deja de ser punto de referencia el art. 148.1.17 CE, quedando únicamente el art. 149.1.30. CE. Sólo quedaron pendientes de traspaso tres funciones concretas en materia educativa: la gestión del profesorado que imparte las enseñanzas de la materia de religión ${ }^{38}$, las funciones ejecutivas relacionadas con los procedimientos de homologación y convalidación de títulos y estudios extranjeros ${ }^{39}$ y la gestión de las becas y ayudas al estudio.

Respecto a la materia educativa, también fueron relevantes las reformas estatutarias de la llamada «tercera fase». La fecha de inicio de la tercera fase de reformas estatutarias de nuestro Estado Autonómico se puede situar el 11 de abril de 2006, fecha en la que se publica en el BOE la reforma del Estatuto de la Comunidad Valen-

Estado a la Comunidad de Castilla y León; Real Decreto 96/1996, de 26 de enero, sobre traspaso de funciones y servicios de la Administración del Estado a la Comunidad Autónoma de Aragón; Real Decreto 95/1996, de 26 de enero, sobre traspaso de funciones y servicios de la Administración del Estado a la Comunidad Autónoma de La Rioja; Real Decreto 324/1996, de 23 de febrero, sobre traspaso de funciones y servicios de la Administración del Estado a la Comunidad Autónoma de Castilla-La Mancha; Real Decreto 1382/1996, de 7 de junio, sobre traspaso de funciones y servicios de la Administración del Estado a la Comunidad Autónoma de Cantabria; Real Decreto 2243/1996, de 18 de octubre, sobre traspaso de funciones y servicios de la Administración del Estado a la Comunidad Autónoma de las Islas Baleares.

37 Real Decreto 1876/1997, de 12 de diciembre, sobre traspaso de funciones y servicios de la Administración del Estado a la Comunidad Autónoma de las Islas Baleares; Real Decreto 1826/1998, de 28 de agosto, sobre traspaso de funciones y servicios de la Administración del Estado a la Comunidad Autónoma de La Rioja; Real Decreto 1982/1998, de 18 de septiembre, sobre traspaso de funciones y servicios de la Administración del Estado a la Comunidad Autónoma de Aragón; Real Decreto 2671/1998, de 11 de diciembre, sobre traspaso de funciones y servicios de la Administración del Estado a la Comunidad Autónoma de Cantabria; Real Decreto 926/1999, de 28 de mayo, sobre traspaso de funciones y servicios de la Administración del Estado a la Comunidad de Madrid; Real Decreto 938/1999, de 4 de junio, sobre traspaso de funciones y servicios de la Administración del Estado a la Comunidad Autónoma de la Región de Murcia; Real Decreto 1340/1999, de 31 de julio, sobre traspaso de funciones y servicios de la Administración del Estado a la Comunidad de Castilla y León; Real Decreto 1801/1999, de 26 de noviembre, sobre traspaso de funciones y servicios de la Administración del Estado a la Comunidad Autónoma de Extremadura; Real Decreto 1844/1999, de 3 de diciembre, sobre traspaso de funciones y servicios de la Administración del Estado a la Comunidad Autónoma de Castilla-La Mancha; Real Decreto 2081/1999, de 30 de diciembre, sobre traspaso de funciones y servicios de la Administración del Estado al Principado de Asturias.

38 Todas las Comunidades Autónomas tienen actualmente la gestión de los profesores de religión, exceptuando Aragón, Andalucía, Canarias y Cantabria. Canal Muñoz, J. (2018). «La competencia estatal en materia de becas y ayudas al estudio: fundamento y alcance», Revista de Derecho Político, 102, p. 142.

39 Se han transferido funciones de homologación y convalidación de títulos y estudios extranjeros, de carácter no universitario a Galicia (Real Decreto 1319/2008, de 24 de julio), Cataluña (Real Decreto $1385 / 2008$, de 1 de agosto) y País Vasco (Real Decreto 893/2011, de 24 de junio). Vid. Canal Muñoz, J. (2018), ob. cit., p. 142.

(C) UNED. Revista de Derecho Politico

N.o 111, mayo-agosto 2021, págs. 45-76 
ciana, a la que seguirán las reformas de los Estatutos de Cataluña, Andalucía, Illes Balears, Aragón y Castilla y León. Esta fase tiene como uno de sus objetivos generales garantizar unos ámbitos competenciales exclusivos autonómicos vedados a la intervención estatal. Para ello, en materias como la educativa, donde la competencia es compartida, los propios Estatutos de Autonomía tratarían de concretar la competencia autonómica y por extensión la estatal. Esta fase no supone una modificación sustancial en materia de competencias educativas, pero sí un intento normativo por precisar el ámbito de la legislación básica estatal en la materia ${ }^{40}$. No obstante, de esta fase quedan dos cuestiones claras.

Por una parte, aunque en algún supuesto los Estatutos califiquen como exclusiva la competencia educativa autonómica, tal calificación estatuaria decae y, pese a su tenor literal, habrá de entenderse como no exclusiva o «impropiamente exclusiva» de la Comunidad Autónoma (STC 31/2010, de 28 de junio, FJ 77).

Por otra parte, si bien la precisión normativa de los Estatutos de Autonomía puede servirnos para saber el uso que hasta entonces había hecho el legislador estatal de su competencia de bases y, por extensión, la competencia dejada a las Comunidades Autónomas, en absoluto es una foto fija. La STC 31/2010, de 28 de junio, deja claro que, igual que el legislador estatal no puede desarrollar con carácter general el Titulo VIII a través de las leyes de armonización, tampoco los Estatutos de Autonomía son la vía adecuada para precisar el ámbito de la legislación básica ${ }^{41}$. De hecho, la definición de «lo básico» deja un gran margen de apreciación al legislador estatal. Incluso se deja abierta la posibilidad de los reglamentos como normas reguladoras de bases y se admite que regulen «el contenido normativo mínimo» y no sólo ser principios o estándares normativos (art. $111 \mathrm{EAC})^{42}$.

\section{LA FINANCIACIÓN DE LA EDUCACIÓN}

En un ámbito como el educativo, donde -como hemos visto- la competencia es compartida, el Estado debería financiar a través de sus Presupuestos Generales las decisiones que adopta en el marco de su competencia legislativa básica. Entre esas

40 Vid. paradigmáticamente arts. 131 y 172 Estatuto de Autonomía de Cataluña.

41 Fue una cuestión que despertó una viva polémica doctrinal. Claramente a favor de que los Estatutos de Autonomía fijaran el contenido de las bases se manifestó Viver I Pi-Sunyer, C. (2006). «En defensa de los Estatutos de Autonomía como normas jurídicas delimitadoras de competencias: contribución a una polémica jurídico constitucional», en El Estado Autonómico: actas de las XI Jornadas de la Asociación de Letrados del Tribunal Constitucional, celebradas en Palma de Mallorca en octubre de 2005, Centro de Estudios Políticos y Constitucionales. Una crítica, que compartimos, a la modulación de las bases estatales por un Estatuto de Autonomía puede verse en De La Quadra-Salcedo Janini (2004). «¿Es el Estatuto de Autonomía una norma capaz de modular el alcance de la legislación básica del Estado?», Revista Española de Derecho Constitucional, núm. 72.

42 Roig Molés, E. (2006). «La reforma del Estado de las Autonomías: ¿ruptura o consolidación del modelo constitucional de 1978?», REAF, núm. 3, pp. 180-181. 
decisiones, el Estado ha fijado los requisitos mínimos que han de reunir los centros docentes para impartir enseñanzas con garantía de calidad (art. 14 LODE, Real Decreto 132/2010, de 12 de febrero) y las normas básicas sobre conciertos educativos (Real Decreto 2377/1985, de 18 de diciembre). Por tanto, la financiación de los costes directos de escolarización en las enseñanzas obligatorias (inversión en centros públicos o financiación de los conciertos educativos) debería correr a cargo del Estado. Si es decisión del legislador estatal cubrir también los costes indirectos (los libros, el transporte escolar o los comedores ${ }^{43}$ o costes de la enseñanza no obligatoria, deberá quedar también reflejado en sus presupuestos. Igualmente, toda mejora que se prevea desde una Comunidad Autónoma en ejercicio de su competencia legislativa de desarrollo, tanto en costes indirectos de la enseñanza obligatoria como no obligatoria, tiene que estar financiada por los presupuestos autonómicos. Además, el Estado podría, en ejercicio de su poder de gasto y en el marco de la voluntariedad, incentivar determinadas políticas autonómicas.

Pues bien, en la práctica, frente al peso decisivo que tiene el legislador estatal en materia educativa, con una regulación de detalle en leyes y reglamentos, la financiación de la educación recae fundamentalmente, a partir del año 2000, en las Comunidades Autónomas, siendo éstas las que terminan pagando, con recursos de libre disposición o transferencias del Estado (imposible discernir en muchos casos), las decisiones legislativas del Estado. Tal y como puede observarse en la serie histórica, mientras los presupuestos estatales en educación estaban por encima del $3 \%$ del gasto total, a partir de 2000 pasan a representar el 0,6\% del presupuesto total ${ }^{44}$.

A continuación se analizan los principales gastos educativos y su financiación.

\subsection{La inversión en centros y la financiación de conciertos}

La gratuidad de la enseñanza obligatoria impuesta constitucionalmente (art. 27.4 CE) obliga a los poderes públicos a hacerse cargo directamente de los costes de construcción y mantenimiento de sus propios centros o concertar con los privados. En virtud de esta obligación, el art. 17 LODE señala que «la creación y supresión de centros

43 El Defensor del Pueblo se ha manifestado favorable a la extensión de la gratuidad a todos los costes de la enseñanza obligatoria, ya que considera que «la gratuidad ha de abarcar a todo el conjunto de actividades y medios que resultan precisos para que los alumnos cursen las enseñanzas correspondientes. No debe perderse de vista que la Constitución no sólo define la enseñanza básica como gratuita, sino también como obligatoria. Y del establecimiento de ese deber constitucional —impuesto a los menores destinatarios de la norma — ha de deducirse el correlativo deber público de proporcionar todos los medios imprescindibles para que pueda ser cumplido. Y en ello no influye la naturaleza pública o privada de los centros educativos, ya que el dato de referencia es, en todo caso, el de las enseñanzas que se cursen y su carácter obligatorio». Defensor del Pueblo (2013). Estudio sobre la Gratuidad de los Libros de Texto: programas, ayudas, préstamos y reutilización. Madrid, p. 9.

44 https://datosmacro.expansion.com/estado/presupuestos/espana?sc=PR-G-F-32 (consulta 10/6/2020).

(C) UNED. Revista de Derecho Politico

N.o 111, mayo-agosto 2021, págs. 45-76 
públicos se efectuará por el Gobierno o por el Consejo de Gobierno de la Comunidad Autónoma correspondiente, en el ámbito de sus respectivas competencias».

Como hemos visto más arriba, el Estado ha fijado los requisitos mínimos que han de reunir los centros docentes para impartir enseñanzas con garantía de calidad (art. 14 LODE, Real Decreto 132/2010, de 12 de febrero) y las normas básicas sobre conciertos educativos (Real Decreto 2377/1985, de 18 de diciembre). Por tanto, la financiación de los costes directos de escolarización en las enseñanzas obligatorias (inversión en centros públicos o financiación de los conciertos educativos) debería correr a cargo del Estado, permitiendo a las Comunidades Autónomas establecer mejoras financiadas con sus presupuestos. De acuerdo con ello, en la práctica, tanto la creación de centros docentes como la financiación de la concertada corre a cargo de los Presupuestos Generales del Estado, aunque con posibilidad de mejora por parte de las Comunidades Autónomas.

Respecto a la financiación de los conciertos educativos, y en coherencia con lo señalado, el art. 117 LOE (en la redacción dada por la LOMCE sin modificar por la LOMLOE) señala que los presupuestos generales del Estado fijan el importe mínimo por unidad escolar, incluyendo los gastos de personal docente, gastos variables y otros gastos. Los presupuestos de las Comunidades Autónomas podrían mejorar esa financiación. En la práctica, al ser las Comunidades Autónomas las que tienen la última palabra en la concesión de los conciertos, en función de la mayoría parlamentaria autonómica se observa una mayor o menor concesión de conciertos y, por tanto, de gasto en este ámbito ${ }^{45}$.

Al pertenecer al Estado la regulación de mínimos en materia de creación de centros docentes también retiene en sus presupuestos los gastos de «inversión nueva». En la práctica, para cubrir los gastos de inversión se han desarrollado convenios entre el Estado y las Comunidades Autónomas, donde la aportación financiera de las mismas proviene, total o parcialmente, de los Fondos de Compensación Interterritorial, es decir, también de los Presupuestos Generales del Estado (art. 18.2 LOFCA). El requisito del común acuerdo exigido en estos casos por el art. 16.7 LOFCA será declarado constitucional (STC 250/1988, de 20 de diciembre, FJ 4) fundamentando la atribución estatal en el hecho de ser el Fondo una forma de colaboración financiera ex art. 157.3 CE, en el origen de los recursos financieros y en la necesidad de garantizar el principio de solidaridad de acuerdo con el art. 138.1 $\mathrm{CE}^{46}$. En cambio, no veo

45 Sobre la problemática entorno a la financiación de los conciertos en las distintas Comunidades Autónomas vid. Vidal Prado, C. (2018). «Descentralización y derechos educativos, 40 años después», en Álvarez Vélez, M. I. y Vidal Prado, C. (coords). La Constitución Española: 1978-2018: Manual, Ediciones Francis Lefebvre, p. 340. También Vidal Prado, C. (2017). El derecho a la educación en España. Bases constitucionales para el acuerdo y cuestiones controvertidas, Marcial Pons, pp. 115-116.

46 Algunos autores consideran que la intervención estatal está legitimada por el art. 138.1 CE. Falcón y Tella, R. (1986). La compensación financiera interterritorial, Madrid, Congreso de los Diputados, p. 206. Por el contrario, Medina Guerrero considera inconstitucional la exigencia de acuerdo para la elección del proyecto de inversión autonómico a financiar por el FCI: niega que sea una forma de colaboración financiera, sino tan sólo una fuente de ingresos de las CCAA, salvo en el caso de que los ingresos 
inconveniente en la no exigencia del convenio en el caso de financiación de la construcción por la propia Comunidad Autónoma. Al igual que ocurre con el caso de la creación de universidades públicas (antes arts. 5.1 y 58.1 LORU de 1983 y ahora art. 4 LOU), la creación de un centro educativo puede ser decidido y financiado exclusivamente por la Comunidad Autónoma.

También desde el momento en el que el legislador estatal decidió la gratuidad del segundo ciclo de la educación infantil (art. 15.2 LOE) y los requisitos mínimos para su implantación ${ }^{47}$, debería financiarse con sus presupuestos los costes directos de ese ciclo, tales como la creación de nuevos centros o financiación de los ya existentes, así como el concierto con las entidades privadas correspondientes. Así se dispone en la Disposición Adicional 24a de la LOE: «Los Presupuestos Generales del Estado correspondientes al ámbito temporal de aplicación de la presente ley incorporarán progresivamente los créditos necesarios para hacer efectiva la gratuidad del segundo ciclo de la educación infantil a la que se refiere el artículo 15.2».

Diferente es el caso del primer ciclo de la educación infantil o del Bachillerato en centros privados. Ni el constituyente ni el legislador estatal han establecido su gratuidad y son las Comunidades Autónomas quienes tendrían que determinar los requisitos necesarios para su puesta en práctica y asumir, con cargo a sus presupuestos, su creación o concierto. Veremos más adelante su papel.

\subsection{Las becas estatales en los Presupuestos Generales del Estado: regulación y financiación estatal; ¿gestión descentralizada?}

El ámbito de las becas al estudio es un ámbito que mantiene una coherencia entre la responsabilidad legislativa y financiación. De hecho, la regulación de las becas y ayudas al estudio tanto en la enseñanza no universitaria como en la universitaria dependerá de quién las financie. En este sentido, en las becas financiadas por los Presupuestos Generales del Estado se ha reservado el Estado la regulación plena. Buena

\footnotetext{
de Fondo se destinen a un proyecto conjunto (art. 18 LOFCA) siendo este convenio voluntario; incluso si se considerara una forma de colaboración, no cabría otorgar al Estado potestades tan grandes que afectaran a las competencias autonómicas; indica el peligro de afirmar que el origen de los recursos legitimaría la intervención estatal en las decisiones sobre el destino de los mismos poniendo el ejemplo de la participación en los ingresos del Estado; y niega que el art. 138.1 sea una cláusula atributiva de competencias. Medina Guerrero, M. (1992). La incidencia del sistema de financiación en el ejericio de las competencias de las Comunidades Autónomas, Madrid, CEC, pp. 385-389. Frente a esta argumentación, aquí se sostiene que desde el momento en el que se consideran básicos los requisitos mínimos que han de tener los centros de educación, en virtud del art. 149.1.30 CE, es al Estado al que corresponderá financiarlos y, en colaboración con la Comunidad Autónoma, como Administración competente en la elaboración del plan de inversión y ejecución, decidir el destino final de los recursos.

47 La gratuidad de la enseñanza infantil en los centros públicos ya se reconoció en el art. 52 del Real Decreto 82/1996, de 26 de enero.
}

(C) UNED. Revista de Derecho Politico

N.o 111, mayo-agosto 2021, págs. 45-76 
parte de los recursos destinados a la política educativa en los Presupuestos Generales del Estado se destinan a becas y ayudas a estudiantes ${ }^{48}$.

El sistema de becas, previsto ya en la Ley 14/1979, General de Educación, ha sido recogido en la legislación orgánica que desarrolla el art. 27 CE. Así, el art. 26.3 LORU establecía que «con objeto de que nadie quede excluido del estudio en la Universidad por razones económicas, el Estado y las Comunidades Autónomas, así como las propias Universidades, instrumentarán una política general de becas, ayudas y créditos a los estudiantes y establecerán, asimismo, modalidades de exención parcial o total del pago de tasas académicas». La LODE prevé en su art. 1.2 que «Todos, asimismo, tienen derecho a acceder a niveles superiores de educación, en función de sus aptitudes y vocación, sin que en ningún caso el ejercicio de este derecho esté sujeto a discriminaciones debidas a la capacidad económica, nivel social o lugar de residencia del alumno». También el art. 6.3. j de la LODE (en redacción dada por la LOMLOE) reconoce el derecho del alumnado a «recibir las ayudas y los apoyos precisos para compensar las carencias y desventajas de tipo personal, familiar, económico, social y cultural, especialmente en el caso de presentar necesidades educativas especiales, que impidan o dificulten el acceso y la permanencia en el sistema educativo». Por su parte, la LOGSE, con mayor precisión, disponía que «para garantizar la igualdad de todos los ciudadanos en el ejercicio del derecho a la educación, se arbitrarán becas y ayudas al estudio que compensarán las condiciones socioeconómicas desfavorables de los alumnos y se otorgarán en la enseñanza postobligatoria, además, en función de la capacidad y rendimiento escolar. Se establecerán, igualmente, los procedimientos de coordinación y colaboración necesarios para articular un sistema eficaz de verificación y control de las becas concedidas» (art. 66.1).

Actualmente, tanto en el ámbito no universitario como en el universitario, el gobierno central, en las becas financiadas con sus presupuestos, regula los requisitos básicos para su obtención (artículo 83 LOE; art. 45.1 Ley Orgánica 6/2001, de 21 de diciembre, de Universidades -LOU-). Por tanto, decisión y financiación van de la mano en el sistema nacional de becas en virtud de la competencia sobre las bases del sistema educativo reconocida al legislador estatal en el art. 149.1.30 CE (STC 13/1992, FJ 13; STC 330/1993, de 13 de noviembre). Más controvertida es la gestión de las becas.

Ya desde el comienzo, la DA segunda del Real Decreto 2298/1983, de 28 de julio, preveía que la convocatoria y concesión de estas becas y ayudas se ajustará en las Comunidades Autónomas con competencia plena en materia educativa a lo que dispongan los correspondientes Reales Decretos de traspasos de funciones y servicios. No obstante, en el traspaso de las funciones y servicios no se incluía inicialmente la gestión de las becas.

48 Rueda López, N. (2015). «La descentralización de la educación no universitaria en España: gasto público y resultados académicos», en Caballero Sánchez, R. (dir.), Sistema educativo y descentralización territorial, Iustel, pp. 396-397. 
La STC 330/1993, de 13 de noviembre, reconoce la necesidad de que se cuente con la participación de las Comunidades Autónomas en su gestión (FFJJ 3 y 4). Más contundente se muestra respecto a las competencias autonómicas en la gestión de las becas y ayudas al estudio la STC 188/2001, de 20 de septiembre. En ella el TC resuelve dos conflictos positivos de competencia acumulados planteados por el Consejo Ejecutivo de la Generalidad de Cataluña contra, respectivamente, la Orden del Ministerio de Educación y Ciencia de 15 de junio de 1994, por la que se convocan becas y ayudas al estudio de carácter general para estudios universitarios y medios para el curso académico 1994-1995, y la Orden de 30 de junio de 1997, del Ministerio de Educación y Cultura, por la que se convocan becas y ayudas al estudio de carácter general, para estudios universitarios y medios para el curso 1997-1998. En esta Sentencia, si bien considera que una regulación detallada en este sector educativo puede considerarse incluido en el concepto de bases (FJ 10), no considera lo mismo respecto a la gestión. Los inconvenientes alegados por el Estado para su descentralización pueden ser superados, según el TC, a través de mecanismos de cooperación y coordinación (FJ 11).

En aplicación de la jurisprudencia constitucional se aprueba el Real Decreto $1721 / 2007$, de 21 de diciembre (modificado parcialmente por el Real Decreto $472 / 2014$, de 13 de junio), por el que se establece el régimen de las becas y ayudas al estudio personalizadas. Se incluyen tanto las ayudas dirigidas a la enseñanza obligatoria (para cubrir costes indirectos como transporte, comedor o libros), como las ayudas a la enseñanza no obligatoria. Tal y como establece esta normativa, la gestión de estas ayudas corresponderá a las Comunidades Autónomas, reservándose el Estado exclusivamente la gestión de las ayudas «destinadas a cursar estudios en comunidad autónoma distinta a la del domicilio familiar del estudiante, las destinadas a los alumnos de la Universidad Nacional de Educación a Distancia, del Centro de Investigación y Desarrollo de la Educación a Distancia, de Ceuta, de Melilla y de los centros españoles en el exterior» (art. 1.4 RD 1721/2007). Esta normativa recoge que, a partir del momento en que la Comunidad Autónoma suscriba el acuerdo de traspaso de estas funciones, la gestión quedará descentralizada.

La STC 25/2015 ha declarado inconstitucional que la Administración General del Estado se reserve la gestión centralizada de las becas de movilidad, «destinadas a cursar estudios en comunidad autónoma distinta a la del domicilio familiar del estudiante». La STC 95/2016 considera inconstitucional la atribución a órganos de la Administración General del Estado de las facultades de resolución y pago a los beneficiarios del componente variable de las becas generales.

En definitiva, la jurisprudencia constitucional ha venido realizando una tarea de eliminación progresiva de funciones ejecutivas concretas que se reservaban a la gestión centralizada del ministerio. La gestión descentralizada del pago (Real Decreto 293/2016), no obstante, exige hacer constar en la convocatoria y en la concesión que son financiadas por el Ministerio de Educación y Ciencia (art. 41.2 RD 1721/2007).

Dos son los inconvenientes que veo en esta línea jurisprudencial. Por una parte, la gestión descentralizada puede tener sentido en los servicios, ya que requieren de

(C) UNED. Revista de Derecho Politico

N.o 111, mayo-agosto 2021, págs. 45-76 
una estructura organizativa en el territorio, pero no en una prestación económica, que puede hoy gestionarse telemáticamente. Por otra parte, una gestión autonómica de una prestación que está regulada y financiada totalmente por el poder central puede generar confusión entre la ciudadanía y con ello difusión de responsabilidades. Desde mi punto de vista, la gestión estatal de una prestación económica regulada y financiada desde el poder central no vulnera la competencia de desarrollo que en este campo pueden tener las Comunidades Autónomas siempre que se les reconozca la posibilidad de completar estas ayudas con una regulación y financiación propia.

A partir del curso 2008/2009 (Real Decreto 675/2008, de 28 de abril, por el que se establecen los umbrales de renta y patrimonio familiar y las cuantías de las becas y ayudas al estudio del Ministerio de Educación, Política Social y Deporte para el curso 2008-2009) se reconoció a las Comunidades Autónomas la posibilidad de conveniar con el Ministerio la cofinanciación de las becas que se concedieran a estudiantes con rentas familiares inferiores a un umbral de renta que la Comunidad Autónoma puede determinar dentro de una horquilla establecida con carácter básico. De este modo se ampliaba la potestad normativa de las administraciones educativas, que podrían adaptar los umbrales de renta comunes a sus peculiaridades socioeconómicas, aunque asumiendo con cargo a sus presupuestos los costes adicionales que pudieran conllevar estas decisiones.

\subsection{El profesorado}

Tal y como hemos señalado más arriba, el legislador estatal determina la formación y el acceso del profesorado no universitario ya que «van a desempeñar sus tareas al servicio de un sistema educativo que es único en todo el territorio nacional» (STC 213/2013, de 19 de diciembre, FFJJ 6, 7 y 8). A partir de aquí las Comunidades Autónomas podrían, por ejemplo, establecer méritos adicionales en la fase de concurso (STC 213/2013, FJ 7). En este sentido, es habitual en las Comunidades con lengua propia establecer como requisito o como mérito el conocimiento de la misma, así como el procedimiento para su acreditación ${ }^{49}$.

Aunque la regulación básica estatal se impone en el profesorado funcionario de las enseñanzas medias y su remuneración básica se fija en los Presupuestos Generales del Estado, las retribuciones complementarias se regulan y financian a través de los presupuestos autonómicos, habiendo diferencias apreciables en los sueldos según las autonomías ${ }^{50}$ y constituyendo esta financiación una parte fundamental del presupues-

49 Meix Cereceda, P. (2015). «La formación y selección del profesorado en el Estado Autonómico», en Caballero Sánchez, R. (dir.), Sistema educativo y descentralización territorial, Iustel, p. 231.

50 Informe UGT. Retribuciones docentes en la Enseñanza Pública 2019-2020. Boletín de Enseñanza Pública, diciembre de 2019. En línea: https://www.fespugt.es/images/PDF/ensenanza/P\%C3\%BAblica/ bolet $\%$ C3\%ADn-p\%C3\%BAblica-retribuciones-docentes-2019-2020-definitivo.pdf (consulta: 2/7/2020). 
to autonómico educativo ${ }^{51}$. En cambio, la remuneración del profesorado funcionario universitario es uniforme en todo el Estado (Real Decreto 1086/1989, de 28 de agosto) y es financiada con los Presupuestos Generales del Estado, aunque se permite su mejora a las Comunidades Autónomas (art. 69 LOU). En el ámbito universitario, la variación autonómica se encuentra básicamente en los profesores contratados, tanto en los méritos exigidos para su acceso ${ }^{52}$ como en su remuneración.

\subsection{Las políticas educativas propias de las Comunidades Autónomas con cargo a sus presupuestos}

El reconocimiento de autonomía política en el ámbito educativo implica que las Comunidades Autónomas no sólo pueden, si sus Estatutos lo permiten, concretar y ejecutar la legislación estatal educativa, sino que en el marco de desarrollo normativo también podrían complementarla, atribuyendo nuevas facetas a los derechos o, incluso, desarrollando en su ámbito competencial alguno que el Estado no haya regulado, siempre que se mantenga una coherencia y coordinación con los reconocidos estatalmente. El deber de promover las condiciones para que la libertad y la igualdad del individuo y de los grupos en que se integra sean reales y efectivas y de remover los obstáculos que impidan o dificulten su plenitud (art. 9.2 CE) parece exigir una interpretación generosa respecto a las posibilidades de las Comunidades Autónomas de complementar y mejorar las políticas educativas estatales en función de sus necesidades propias.

Es en un ámbito como el educativo en donde los Parlamentos autonómicos pueden desarrollar sus mejores virtualidades, para así favorecer «la construcción de unos nuevos hechos diferenciales, pero ahora no basados en más que discutibles legitimidades históricas sino en efectivas y diversas venturas para los ciudadanos que viven en una comunidad autónoma y democrática ${ }^{53}$. En palabras de Stern, desde la libertad no cabe mirar sino con simpatía las pequeñas diferencias que en esta materia puedan producirse ${ }^{54}$. A continuación, se detallan las principales políticas educativas autonómicas.

51 Rueda López, N. (2015), ob. cit., pp. 405-407, 409.

52 Rodríguez-Patrón, P. y Galán, A. (2015). «Descentralización y poder discrecional: la medida de los productos de investigación en Ciencias Jurídicas», en Caballero Sánchez, R. (dir.), Sistema educativo y descentralización territorial, Iustel, pp. 256-260.

53 Contreras Casado, M. (1998). «Notas sobre el legislador de los derechos sociales, económicos y culturales (el caso aragonés)», Nuevos escenarios y nuevos colectivos de los derechos humanos. Monografías de la Revista Aragonesa de Administración Pública, Zaragoza, p. 457.

54 Stern, K. (1989). «Pluralismo territorial y derechos fundamentales», en Pluralismo territorial en la República Federal Alemana, Madrid, MAP, p. 79.

(C) UNED. Revista de Derecho Politico

N.o 111, mayo-agosto 2021, págs. 45-76 
a) Políticas autonómicas en enseñanza no universitaria

La enseñanza no universitaria deja un mayor campo de actuación, a pesar del cierto carácter detallista de las leyes orgánicas aprobadas sobre la materia y de las numerosas normas dictadas en su desarrollo, muchas de ellas de aplicación directa. No obstante, las mejoras introducidas por las autonomías han sido reducidas.

Las leyes autonómicas sobre educación con vocación de regular el sistema educativo no universitario en las respectivas Comunidades Autónomas no son generalizadas y, además, tienen un carácter relativamente superfluo ${ }^{55}$. También se han dictado leyes autonómicas estableciendo la gratuidad de los estudios de bachillerato, formación profesional y artes aplicadas y oficios artísticos en los centros públicos $^{56}$. No obstante, la gratuidad en centros públicos de estos estudios estaba ya proclamada en el art. 1 Ley 12/1987, a la que se remite la DF 4 de la LOE y en el art. 71 del Real Decreto 83/1996. Esto hace la legislación autonómica superflua frente al reconocimiento estatal. Por tanto, exceptuando la legislación autonómica dirigida a la formación de adultos ${ }^{57}$, es en el nivel reglamentario donde la mayor parte de las Comunidades Autónomas despliegan su actividad normativa más novedosa.

El mayor margen de configuración autonómica se ha referido a los contenidos de las asignaturas. En este sentido, el modelo autonómico de Estado en materia educativa se ha traducido, a la postre, en la fijación por el legislador estatal de la estructura de los niveles educativos y de los contenidos mínimos de cada uno de ellos. El resto del «currículum» corresponde a las Comunidades Autónomas, gozando aquéllas con peculiaridades lingüísticas de la posibilidad de incorporar además la enseñanza de la lengua propia.

La LOMCE dividió las asignaturas de educación primaria, educación secundaria obligatoria y bachillerato en tres tipos de materias: troncales, específicas y de libre configuración autonómica. La administración del Estado fijaba las materias troncales, su horario mínimo y mantenía el control de las evaluaciones finales de la Educación Secundaria Obligatoria y Bachillerato. Las Comunidades Autónomas complementaban las materias troncales y fijaban los contenidos de las asignaturas específicas y de libre

55 Han dictado leyes generales educativas el País Vasco (Ley 1/1993, de 19 de febrero, de la Escuela Pública Vasca), Andalucía (Ley 17/2007, de 10 de diciembre, de Educación de Andalucía), Cantabria (Ley de Cantabria 6/2008 de Educación de Cantabria), Cataluña (Ley 12/2009, de 10 de julio, de Educación), Castilla-La Mancha (Ley 7/2010, de 20 de julio, de Educación de Castilla-La Mancha), Extramadura (Ley 4/2011, de 7 de marzo, de educación de Extremadura) o Canarias (Ley 6/2014, de 25 de julio, Canaria de Educación no Universitaria). La normativa educativa de las CCAA puede consultarse en http://www.educacionyfp.gob.es/educacion/mc/lomce/mapa-ccaa.html (consulta 8/6/2020).

56 Vid. leyes 5/1987, de 12 de mayo, de la Comunidad Valenciana; 7/1987, de 26 de junio, de Andalucía; 8/1987, de 25 de noviembre, de Galicia; 18/1987, de 13 de julio, de Cataluña; 1/1988, de 8 de julio, de Canarias.

57 Vid., entre otras, Ley andaluza 3/1990, de 27 de marzo, la catalana 3/1991, de 18 de marzo, la gallega 9/1992, de 24 de julio y la valenciana 1/1995, de 20 de enero. 
configuración autonómica ${ }^{58}$. Esta división entre asignaturas troncales, específicas y de libre configuración ha llevado a una mayor diferenciación en los currículos de las diversas CCAA, que «tienen cada vez menos elementos comunes entre sí» ${ }^{59}$.

De acuerdo con la anterior redacción del art. 14.7 LOE, la regulación de los requisitos mínimos de los centros de educación infantil en el primer ciclo ${ }^{60}$ y su financiación correspondía a las Comunidades Autónomas. Respecto a la regulación, gestión y financiación de la educación infantil de primer ciclo existía hasta ahora una gran disparidad entre autonomías, existiendo un enorme grado de dificultad para conocer las cantidades asignadas a este ciclo ya que los presupuestos autonómicos no hay partidas desagregadas. Sólo Andalucía y País Vasco incluyen programas específicos que permitan contabilizar el gasto en dicha política. En el resto de las Comunidades Autónomas, el gasto se encuentra incluido con el segundo ciclo de educación infantil (de 3 a 6 años) o incluso con educación primaria, por lo que no es posible aislar los recursos destinados a esta política. A pesar de estas dificultades, los cálculos arrojados en esta materia concluyen que los recursos destinados a la educación infantil de primer ciclo son claramente insuficientes ${ }^{61}$. Con la aprobación de la LOMLOE, el nuevo art. 14.7 LOE asigna al gobierno, en colaboración con las CCAA, la regulación de los contenidos educativos, la titulación de los profesionales y los requisitos de los centros del primer ciclo de educación infantil. Se prevé también una ampliación de la gratuidad en el marco de las relaciones intergubernamentales (DA 3 Y 5 LOE en redacción dada por la LOMLOE). Por tanto, se pretende avanzar en la homogeneidad regulativa y de financiación a través de la cooperación interterritorial.

También las Comunidades Autónomas han puesto en marcha diferentes sistemas de gratuidad de libros de texto. Básicamente, hay dos modelos de gratuidad (ayudas directas y préstamo de libros) con diversas variantes según cada comunidad autónoma y la implicación autonómica puede ir de la menor (en Cataluña con una inversión por alumno de 5,75 euros) a la mayor (en Andalucía con 108,3 euros) ${ }^{62}$.

58 Perona Mata, C. (2018). «La regulación del derecho a la educación en las Comunidades Autónomas tras la promulgación de la Ley Orgánica de Educación», Revista de Derecho vLex, núm. 164, p. 5.

59 Informe ANELE (Asociación Nacional de Editores de Libros y Material de Enseñanza). El libro educativo en España. Curso 2019-2020. Madrid, 5 de septiembre de 2019, p. 9. En línea: https://anele.org/ wp-content/uploads/2019/09/190905INF-ANELE-Informe-Libro-Educativo-19-20.pdf (consulta 26/6/20).

${ }^{6}$ Vid. la normativa de las diversas Comunidades Autónomas en el primer ciclo de educación infantil en https://www.educacionyfp.gob.es/educacion/mc/redie-eurydice/sistemas-educativos/organizacion-y-administracion/requisitos-minimos-centros.html (consulta 29/5/20).

61 Castellanos Serrano, C. y Perondi, A. C. (2018). «Diagnóstico sobre el primer ciclo de educación infantil en España (0 a 3 años). Propuesta de implantación de un sistema de educación infantil de calidad y cobertura universal. Estudio de viabilidad económica de la reforma propuesta y de sus impactos socio-económicos», Papeles de Trabajo, 3/18, Instituto de Estudios Fiscales, pp. 7, 21, 46, 62.

62 Informe ANELE (Asociación Nacional de Editores de Libros y Material de Enseñanza). El libro educativo en España. Curso 2019-2020. Madrid, 5 de septiembre de 2019, pp. 15-16, 36. En línea: https://anele. org/wp-content/uploads/2019/09/190905INF-ANELE-Informe-Libro-Educativo-19-20.pdf (consulta 26/6/20).

(C) UNED. Revista de Derecho Politico

N.o 111, mayo-agosto 2021, págs. 45-76 
b) Políticas autonómicas en enseñanza universitaria

La submateria en la que las competencias autonómicas han estado más limitadas es la enseñanza universitaria. A las competencias que ya la LORU de 1983 reservaba al Estado, ha de sumarse la fuerza ampliatoria de las competencias de las propias Universidades que se produce a costa de la de las Comunidades Autónomas. En definitiva, la posibilidad de una política autonómica propia fue inicialmente casi imposible, al menos desde el punto de vista normativo ${ }^{63}$. Incluso desde el punto de vista ejecutivo, permanece en el ámbito de la Administración General del Estado la UNED y la UIMP.

No obstante, a partir de la Ley Orgánica 6/2001, de 21 de diciembre, de Universidades (LOU), las competencias autonómicas adquirieron más relevancia y la mayoría de las autonomías empezaron a aprobar leyes sobre el «sistema» universitario propio $^{64}$. Actualmente son las autonomías las que determinan los presupuestos universitarios, aprueban sus Estatutos, establecen la relación de universidades o reorganizan la universidad en el territorio ${ }^{65}$. También son las Comunidades Autónomas las que pueden fijar los precios de las matrículas, observándose en la actualidad una desigualdad elevada en los precios públicos universitarios entre ellas ${ }^{66}$.

Igualmente, con la LOU, aunque las competencias autonómicas sobre el régimen jurídico del profesorado funcionario universitario siguen siendo inexistentes, se añade en el ámbito normativo autonómico la regulación del régimen jurídico del profesorado contratado (art. 48.6) ${ }^{67}$. Además, también las Comunidades Autónomas, mediante ley, pueden crear universidades públicas y reconocer privadas, aunque el Gobierno central es el que determinará los requisitos básicos para la creación y reconocimiento de Universidades (Art. 4 LOU).

c) Becas y ayudas autonómicas

Por último, tanto en el ámbito universitario como no universitario, y al margen de la gestión de las becas estatales, las Comunidades Autónomas, en virtud de su competencia legislativa de desarrollo, pueden establecer con cargo a sus presupuestos un sistema adicional o complementario de becas y ayudas al del Estado. Para el ámbito universitario así se prevé expresamente en el art. 45.4 LOU. Con la aprobación de la

63 Lasagabaster (1993), ob. cit., p. 39.

64 Embid Irujo, A. (2009). «Derecho a la educación y Comunidades Autónomas», en Embid Irujo, A. (dir.), Derechos económicos y sociales, Iustel, pp. 181-183.

${ }_{65}$ Cotino Hueso, L. (2012), ob. cit., p. 313.

66 Vidal Prado, C. (2018). «Las medidas de austeridad y control de gasto público en España: Sanidad, Educación y Dependencia», en Terol Becerra, M. J. y Adnane, A. (dirs.), Constitución financiera y constitución social, Tirant lo Blanch, p. 39.

67 Destaca, en este sentido, la ley catalana $1 / 2003$, de 19 de febrero, que crea nuevas figuras de profesorado con contrato laboral indefinido que ha permitido el desarrollo de una carrera académica laboral sustitutiva del funcionariado estatal. 
LOMLOE también se reconoce expresamente en el ámbito no universitario (art. 83.6 LOE en redacción dada por la LOMLOE). En estos casos las condiciones de acceso y su cuantía no debería someterse a la legislación del sistema estatal de becas, es decir, al Real Decreto 1721/2007, de 21 de diciembre. Es más. No tendría ningún sentido que las becas autonómicas siguieran los criterios de las becas estatales, ya que resultarían incompatibles entre sí y dificultaría aumentar el número de posibles beneficiarios. El art. 38 del RD 1721/2007, en redacción dada por Real Decreto 1000/2012, de 29 de junio, establece la incompatibilidad de las ayudas estatales «con cualesquiera otros beneficios de la misma naturaleza y finalidad, salvo que el Ministerio de Educación, Cultura y Deporte declare la compatibilidad en casos suficientemente motivados».

En la práctica, desde el año 1985, en que se materializó la transferencia en materia de Universidades al País Vasco (Real Decreto 1014/1985, de 25 de mayo), la Administración educativa vasca hace su propia convocatoria anual de becas y ayudas para el estudio universitario ${ }^{68}$. Estas órdenes, además de atribuir a las instancias autonómicas o universitarias la gestión de las ayudas, regulan algunos requisitos de los solicitantes de la ayuda (edad, condiciones de acceso por razón de distancia, cuantías, ponderación de las notas, renta familiar, etc.) de modo diferente al establecido por la regulación estatal. A partir de ahí, todas las Comunidades Autónomas han desarrollado su propia política de becas y ayudas al estudio ${ }^{69}$.

Sorprendentemente esta práctica, consolidada en nuestro Estado Autonómico y muestra del verdadero sentido que puede tener la autonomía política, se pone en duda, por primera vez, al impugnarse por la Abogacía del Estado la Orden de 22 de julio de 2014, dictada por la Consejera vasca de Educación, Política Lingüística y Cultura, por la que se convocaban becas para realizar estudios universitarios y otros estudios superiores en el año académico 2014-2015, ayudas destinadas a sufragar los gastos de transporte de los estudiantes con especiales dificultades de movilidad y becas de excelencia académica para reconocer y premiar al alumnado universitario de alto rendimiento. Posteriormente se impugna también la Orden de 22 de octubre de 2014, por la que se convocan becas y ayudas al estudio para la escolarización de estudiantes de niveles no universitarios para el curso académico 2014-2015.

La STS 306/2019, de 8 de marzo, con el argumento de que debe garantizarse que «la regulación del sistema de becas se realice sin menoscabo de la garantía de la igualdad en la obtención de las ayudas en todo el territorio nacional» (FJ 3), niega la competencia autonómica de posible mejora de las ayudas estatales con sus propios fondos. El TS argumenta:

68 Vid. las Órdenes de 27 de julio de 1993 y de 28 de junio de 1994, publicadas en el Boletín Oficial del País Vasco de 26 de agosto de 1993 y 8 de julio de 1994.

69 Pueden verse las diferentes ayudas al estudio programadas por las distintas Comunidades Autónomas en: https://www.educaweb.com/contenidos/educativos/becas-ayudas-premios/becas-comunidades-autonomas-estudiar/ (consulta el 20 de mayo de 2020).

(C) UNED. Revista de Derecho Politico

N.o 111, mayo-agosto 2021, págs. 45-76 
De aceptarse la tesis de la Comunidad recurrente, la regulación autonómica podría establecer un sistema paralelo al del Estado basándose en su propia financiación lo que, a la postre, conduciría a que los estudiantes, dependiendo del lugar de residencia y de la Comunidad en que quieran cursas sus estudios universitarios, no tendrían las mismas oportunidades, pues el sistema de ayudas sería distinto dependiendo de las asignaciones presupuestarias que cada Comunidad Autónoma destinase a tal fin, favoreciéndose a aquellos estudiantes que tuvieran la fortuna de residir en Comunidades Autónomas con mayor disponibilidad financiera, lo que introduciría importantes desigualdades en el acceso a la educación por razón del territorio que precisamente la regulación básica en esta materia tiene por finalidad esencial evitar (FJ 3).

Por tanto, según el Tribunal Supremo, no podría admitirse que las Comunidades Autónomas pudieran establecer un sistema de becas complementario al estatal con sus propios fondos. A continuación (FJ 4), en clara incoherencia con lo que acaba de argumentar, parece validar las becas autonómicas financiadas con recursos propios siempre que respeten la normativa básica estatal y entra a valorar si los diferentes preceptos de la Orden vasca entran en contradicción con dicha normativa básica. Parece admitir un sistema de becas autonómicos con cargo a los presupuestos autonómicos, pero con las mismas condiciones establecidas en las estatales, sin posibilidad de flexibilizar o de aumentar los beneficiarios. Esa misma argumentación es seguida por la STS 656/2019, de 21 de mayo.

\subsection{El poder de gasto en el marco de las relaciones intergubernamentales para incentivar determinadas políticas autonómicas}

Una buena parte de los recursos de los Presupuestos Generales del Estado destinados a la educación son transferencias a las Comunidades Autónomas, en el marco de las relaciones intergubernamentales, para orientar el ejercicio de competencias autonómicas educativas en un determinado sentido. Se mueve, por tanto, en el ámbito de la voluntariedad.

Este tipo de transferencias tuvieron una enorme importancia durante los años de aplicación de la LOE. En este sentido se introdujeron programas para incrementar la tasa de escolarización en la educación infantil de primer ciclo (Plan Educa3), programas para desarrollo de las TIC en el mundo educativo (Escuela 2.0), programas para incrementar las tasas de escolarización en educación secundaria postobligatoria, programas de éxito escolar en Primaria y Secundaria ${ }^{70}$. Según el Informe FIDEAS (2019), este tipo de programas estatales en el ámbito de las relaciones intergubernamentales han tenido un impacto positivo en la reducción de las

70 Vid. Programas de Cooperación territorial 2010-2011, Conferencia de Educación, 28 de septiembre de 2010, Ministerio de Educación, en http://www.educacion.gob.es/dctm/ministerio/borizontales/prensaldocumentos/2010/septiembre/04--programas-de-cooperacion-territorial-2010-2011-conferencia-de-educacion.pdf? documentId=0901e72b8049962b (consulta 1/7/2020). 
desigualdades territoriales. Estos programas fueron desarrollados entre 2008 y 2012, y ampliados en algunos casos hasta $2014^{71}$.

\section{CONCLUSIONES Y VALORACIÓN PERSONAL}

La Constitución española de 1978 otorga a las Cortes Generales una amplia competencia para determinar qué aspectos de la educación han de ser comunes para todos los españoles. A partir de ese mínimo común, que ha de definir el Parlamento estatal, las Comunidades Autónomas pueden establecer algunas peculiaridades y, sobre todo, mejoras en la prestación. No obstante, para que este diseño constitucional funcione adecuadamente en un derecho como el de la educación, con una faceta claramente prestacional, debe existir una coherencia entre las competencias educativas y su financiación, de manera que los ciudadanos podamos distinguir las distintas responsabilidades.

En la práctica, el modelo autonómico de Estado en materia educativa se ha traducido, básicamente, en la fijación por el legislador estatal de la estructura de los niveles educativos y de los contenidos mínimos de cada uno de ellos. El resto del «currículum» corresponde a las Comunidades Autónomas, gozando aquéllas con peculiaridades lingüísticas de la posibilidad de incorporar además la enseñanza de la lengua propia. Actualmente, la distinción que hizo la LOMCE entre asignaturas troncales, específicas y de libre configuración autonómica ha llevado a una mayor diferenciación en los contenidos de las asignaturas entre las autonomías. Desde mi punto vista, esta diferenciación resulta poco justificada. Por una parte, conlleva una inevitable repercusión en los costos de edición, ya que se tiene que hacer diferentes libros según las Comunidades Autónomas. Pero, sobre todo, no creo que existan peculiaridades autonómicas que permitan «complementar» con diferentes contenidos las matemáticas, la biología o el francés.

La diversidad autonómica cobra todo su sentido, sin embargo, en la capacidad de mejora en la prestación educativa que tienen las Comunidades Autónomas en virtud de su competencia de desarrollo. No obstante, se trata de un campo que ha sido insuficientemente utilizado y difícilmente evaluable. Los ámbitos de las mejoras se han centrado fundamentalmente en los programas autonómicos de material escolar y en la regulación y financiación de las escuelas infantiles de primer ciclo. Así, por ejemplo, en el caso de la financiación del primer ciclo de la educación infantil en España, exceptuando Andalucía y País Vasco, el resto de las Comunidades Autónomas incluyen este gasto en su presupuesto con el segundo ciclo de educación infantil (de 3 a 6 años) o incluso con educación primaria. Ello hace imposible valorar el coste de la mejora autonómica.

${ }^{71}$ Castellanos Serrano y Perondi (2018), ob. cit, p. 25.

(C) UNED. Revista de Derecho Politico

N.o 111, mayo-agosto 2021, págs. 45-76 
Por otra parte, frente al peso decisivo que tiene el legislador estatal en materia educativa, con una regulación de detalle en leyes y reglamentos, la financiación de la educación recae fundamentalmente, a partir del año 2000, en las Comunidades Autónomas, siendo éstas las que terminan pagando, con recursos de libre disposición o con transferencias estatales (imposible en la mayoría de las ocasiones distinguirlo) ${ }^{72}$, las decisiones legislativas del Estado. En concreto, no parece coherente que siendo el Estado quien regula el profesorado funcionario, por «desempeñar sus tareas al servicio de un sistema educativo que es único en todo el territorio nacional» (STC 213/2013, de 19 de diciembre, FFJJ 6, 7 y 8), la financiación del mismo en el caso universitario corra a cargo fundamentalmente del Estado y en el no universitario corra buena parte a cargo de los presupuestos autonómicos, observándose diferencias sustanciales de sueldo en función de las autonomías. La financiación fundamentalmente estatal de las retribuciones del profesorado permitiría al Estado no solo incorporar medidas de reducción de su plantilla, tal y como se hizo por Decreto-ley 14/2012, de 20 de abril y por los Presupuestos Generales del Estado ${ }^{73}$, sino también su ampliación en un momento como el generado por la crisis del coronavirus.

Por último, en aras a evitar la confusión de tareas, y en contra de la jurisprudencia del Tribunal Constitucional y de la última del Tribunal Supremo, se aboga por la gestión centralizada de las becas y ayudas financiadas por el Estado y por una interpretación amplia de las competencias autonómicas para crear un sistema propio de becas y ayudas que complemente al estatal.

\section{Title}

The financing of education in the Autonomous State and its coherence with the distribution of educational competences

\section{Summary}

1. Introduction. 2. Historical background. 3. Distribution of competences in education in the Spanish Constitution. 4. The powers assumed by the state legislator. 5 . The assumption of powers in education by the Autono-

72 De hecho, en los diferentes estudios en los que se disgrega el gasto educativo entre administraciones se hace normalmente atribuyendo el gasto a «su ejecutor final», y no al que lo financia Vid. De La Fuente, A. (2018). «Gasto educativo por regiones y niveles en 2015 y su evolución desde el 2000», BBVA Research 18/10, pp. 2, 4, 11, 13. En línea: https://www.bbvaresearch.com/wp-content/ uploads/2018/09/Datos-gasto-edu-2000-15.pdf (consulta 29 de junio de 2020).

73 Vidal Prado, C. (2018), ob. cit., p. 30-43. 
mous Communities. 6. Financing of education. 6.1. Investment in centers and financing of concerts. 6.2. State scholarships in the General State Budgets: state regulation and financing; Decentralized management? 6.3. The teachers. 6.4. The educational policies of the Autonomous Communities charged to their budgets. 6.5. The spending power within the framework of intergovernmental relations to incentivize certain autonomous policies. 7. Conclusions and personal assessment.

\section{Resumen}

La Constitución española de 1978 otorga a las Cortes Generales una amplia competencia para determinar qué aspectos de la educación han de ser comunes para todos los españoles. A partir de ese mínimo común, que ha de definir el Parlamento estatal, las Comunidades Autónomas pueden establecer algunas peculiaridades y, sobre todo, mejoras en la prestación. No obstante, para que este diseño constitucional funcione adecuadamente en un derecho como el de la educación, con una faceta claramente prestacional, debe existir una coherencia entre las competencias educativas y su financiación, de manera que los ciudadanos podamos distinguir las distintas responsabilidades.

A lo largo de este artículo se analiza el sistema de distribución competencial en la prestación educativa para, a continuación, valorar su congruencia con la financiación de la misma. En primer lugar, se hace un recorrido histórico de la distribución de competencias en materia educativa. A continuación, se hace un análisis de la distribución de competencias educativas en la Constitución de 1978, para concretar, seguidamente, las competencias asumidas por el legislador estatal y las autonomías en esta materia. Con el objetivo de analizar la congruencia entre esta distribución de competencias y su financiación, se analiza la responsabilidad financiera en las principales partidas educativas, así como las mejoras prestacionales incluidas en los presupuestos autonómicos y los programas estatales en el marco de las relaciones intergubernamentales.

Se concluye que, mientras no parecen muy justificadas las diferencias curriculares entre autonomías, la diversidad autonómica en un ámbito como el educativo cobra todo su sentido en mejoras prestacionales como la financiación de material escolar o de la educación infantil de primer ciclo. No obstante, la forma de incluir las partidas en sus presupuestos y su diferente contabilización impide una valoración precisa de las mismas. Por otra parte, también se considera que materias financiadas hoy por los presupuestos autonómicos debieran de financiarse por los Presupuestos Generales del Estado, de acuerdo con el alto grado de centralización normativa. En aras a una mayor claridad en la asunción de responsabilidades se aboga por una gestión centralizada de ayudas financiadas completamente por el Estado. También se propone una interpretación amplia en torno a la capacidad de las Comunidades Autónomas para crear su propia política de becas.

(C) UNED. Revista de Derecho Politico

N.o 111, mayo-agosto 2021, págs. 45-76 


\begin{abstract}
The Spanish Constitution of 1978 grants the Cortes Generales broad jurisdiction to determine which aspects of education must be common to all Spaniards. From that common minimum, to be defined by the State Parliament, the Autonomous Communities can establish some peculiarities and, above all, improvements in the provision. However, for this constitutional design to work properly in a right such as education, with a clearly provision aspect, there must be coherence between educational competences and their financing, so that citizens can distinguish between different responsibilities.

Throughout this article, we analyze the system of competence distribution in educational provision, and then assess its consistency with its financing. First, a historical overview of the distribution of competences in educational matters is made. Next, an analysis is made of the distribution of educational competences in the 1978 Constitution, to specify, next, the competences assumed by the state legislator and the autonomies in this matter. In order to analyze the congruence between this distribution of competences and their financing, financial responsibility in the main educational items is analyzed, as well as the improvements included in the regional budgets and state programs in the framework of intergovernmental relations.

It is concluded that, although the autonomic diversity in an area such as education takes on its full meaning in improvements such as the financing of school supplies or early childhood education, the way to include the items in their budgets and their different accounting prevents an accurate assessment of them. On the other hand, it is also considered that matters financed today by the autonomous budgets should be financed by the General State Budgets, in accordance with the high degree of regulatory centralization. In the interests of greater clarity in the assumption of responsibilities, a centralized management of aid financed entirely by the State is advocated. A broad interpretation of the ability of the Autonomous Communities to create their own scholarship policy is also proposed.
\end{abstract}

\title{
Palabras clave
}

Estado Autonómico; educación; competencias; financiación

\section{Keywords}

Autonomous State; education; competencias; financing 